\title{
Olivier Meuwly, Liberté et société. Constant et Tocqueville face aux limites du libéralisme moderne
}

\section{Claude Rétat}

\section{(2) OpenEdition}

10 Journals

\section{Édition électronique}

URL : http://journals.openedition.org/studifrancesi/36321

DOI : 10.4000/studifrancesi.36321

ISSN : 2421-5856

Éditeur

Rosenberg \& Sellier

\section{Édition imprimée}

Date de publication : 1 juillet 2005

Pagination : 177-178

ISSN : 0039-2944

\section{Référence électronique}

Claude Rétat, "Olivier Meuwly, Liberté et société. Constant et Tocqueville face aux limites du libéralisme moderne », Studi Francesi [En ligne], 145 (XLIX | I) | 2005, mis en ligne le 30 novembre 2015, consulté le 19 avril 2021. URL : http://journals.openedition.org/studifrancesi/36321 ; DOI : https://doi.org/ 10.4000/studifrancesi.36321

Ce document a été généré automatiquement le 19 avril 2021.

\section{(c)}

Studi Francesi è distribuita con Licenza Creative Commons Attribuzione - Non commerciale - Non opere derivate 4.0 Internazionale. 


\title{
Olivier Meuwly, Liberté et société. Constant et Tocqueville face aux limites du libéralisme moderne
}

\author{
Claude Rétat
}

\section{RÉFÉRENCE}

OLIVIER MEUWLY, Liberté et société. Constant et Tocqueville face aux limites du libéralisme moderne, Genève, Droz, 2002, pp. 258.

1 L'auteur souhaite montrer la richesse de la pensée libérale, questionner le libéralisme à travers deux de ses grandes figures, dans une intention contemporaine plus encore que moderne, puisqu'il s'agit, fondamentalement, de trouver en eux des «outils» pour penser la société post-dix-neuf-cent-soixante-huitarde, grâce à des effets de comparaison et de miroir. "C'est donc bien une société, foncièrement romantique, comme la société post-soixante-huitarde, qu'il [Tocqueville] étudie, à travers la société américaine»; «Constant et Tocqueville n'ont donc rien perdu de leur actualité. Certes, on a l'impression de se retrouver à la case départ, comme il y a deux siècles, mais le problème n'est pas là»... Le problème est bien là pourtant, et il est difficile d'affirmer et de retirer à la fois. Je dois dire ma profonde méfiance pour ce genre d'«impression», si elle doit motiver, sous-tendre et conditionner la lecture et l'analyse. Pour suivre Olivier Meuwly dans ses conclusions, il est clair qu'il faudrait d'abord partager cette certitude historiquement égocentrique, s'être placé dans le champ des utilisations libérales présentes de la pensée des deux auteurs, accepter le montage temporel et intellectuel par lequel Constant et Tocqueville nous sont donnés comme les deux penseurs pour l'après-68 («pour notre propos, il convient juste de rappeler que la crise des années $60 \mathrm{a}$ reproduit la crise intellectuelle qui avait agité la seconde moitié du XVIII ${ }^{e}$ siècle»...). Il s'agit donc moins, comme le dit l'auteur, d'apporter du nouveau sur des auteurs dont on a déjà tant parlé, que de construire un dispositif. 
2 Le livre est construit en deux parties, la première sur «Le libéralisme de Benjamin Constant», la seconde traite «Du libéralisme de Tocqueville au libéralisme moderne». Chacune rappelle les grands traits biographiques et développe une présentation synthétique de la pensée de chaque auteur, avec des discussions intéressantes, par exemple sur les rapports de Rousseau et de Constant, sur l'influence de Hegel. La volonté synthétique domine: il ne s'agit pas de collationner un trésor de citations, dit 0 . Meuwly, mais de reconstituer des systèmes de pensée. Toute la forme du livre, bref et citant peu, va dans ce sens. L'avantage au niveau de la densité (deux systèmes en deux cents pages) a pour revers qu'il faut accepter d'avoir un peu de tout et de rester sur sa faim. Il faut accepter une prise de vue à très grande échelle de bien des continents: «Romantisme», «Panthéisme», etc... Cela favorise sans doute une réflexion par grandes masses, renforcée par le retrait (hors des rappels biographiques) des marquages chronologiques qui feraient apparaître une évolution dans la pensée et saisiraient la pensée par son évolution. Si Constant et Tocqueville nous sont donnés comme des écrivains et des politiques qui connaissent le pouvoir des mots, cela même apparaît comme un contenu de leur discours, mais non comme une invitation à les lire dans leurs propres procédés d'exposition de démonstration et de persuasion, comme si le texte était chose neutre et transparente. La synthèse d'O. Meuwly n'ignore pas la nuance pourtant, mais sur un autre plan: sa démarche postule le sens du conflictuel, de l'impasse. En exposant des systèmes, $O$. Meuwly cherche non le systématique, mais le problématique, et il est là au cœur de son objet, qu'il définit lui-même comme une pensée libérale qui ne sait pas et ne peut pas se constituer en doctrine. 